\title{
Lumbar Herniated Disc Treated by Microdiscectomy Alone or Microdiscectomy Plus an Interlaminar Shock Absorbing Device: Retrospective Study with Minimum 3-Years Follow-Up
}

\section{Olga Valeria Corriero, Riccardo Morichi, Alessandro Vagaggini, Lorenzo Paoli and Giancarlo Guizzardi*}

Neurosurgical Department, University and City Hospital Careggi, Firenze, Italy

\begin{abstract}
Introduction: The long-term results after surgery for symptomatic lumbar herniated disc have been found to have a low success rate in about one third of patients (30\% to $40 \%$ according to different Authors) who report low back pain rather uncomfortable and restrictive. Nevertheless the long-term results have been scarcely investigated. The aim of this paper is to investigate the long-term results after surgery for lumbar herniated disc in two groups of patients receiving different surgical treatments.
\end{abstract}

Material and method: A retrospective study has been performed, on a series of 89 consecutive patients, affected by lumbar herniated disc, receiving different surgical treatments: a simple microdiscectomy (Group A: 45 cases) or a microdiscectomy associated with the implantation of an interlaminar prosthesis (Group B:44 cases). General and clinical data resulted homogeneously distributed in both Study Groups.

Results: The follow-up ranged from 3 to 5 years. An independent observer was able to evaluate all patients but one, out of the Group B, who resulted lost to follow-up. Two recurrences resulted in Group A $(4,4 \%)$ and 1 in Group B $(2,2 \%)$. The comparison between the 2 Study Groups showed the absence of low back pain during the follow-up period in $74 \%$ of patients who received the implant while patients treated by means of simple standard microdiscectomy remained pain free only in $41 \%$. Furthermore uncomfortable low back pain was registered in $21 \%$ of patients of Group B against $51 \%$ out of Group A. As regards to Macnab Criteria evaluation, that expresses the Quality of Life, $71 \%$ of patients resulted Excellent and 22\% Good in the Group B, while in the Group A 40\% were Excellent and 20\% Good. In both groups no poor results were observed.

Conclusion: The number of patients included in this experience is limited and there is a need for a larger series to confirm observations and results, nevertheless we can affirm the goodness of the path undertaken.

Keywords: Herniated disc; Low back pain; Interlaminar device; Microdiscectomy

\section{Introduction}

Lumbar herniated disc (H D) surgery is most commonly performed electively in patients where conservative therapies have failed to gain improvement of leg pain and disability. Short term results after surgical treatment of symptomatic lumbar HD have been reported to have a high success rate (70-95\%) [1-3]. Factors as age, sex, smoking, duration of leg pain, working status, level of HD and psychosocial aspects have been investigated and demonstrated to be of importance for short-term results after surgery $[2,3]$. On the other hand the long-term results after surgical treatment of symptomatic lumbar HD have been found to have a lower success rate in about one third of the patients $(30 \%$ to $40 \%$ according to different Authors) who report low back pain rather uncomfortable and restrictive [3-6]. In the paper of Weber [4] no significant differences in clinical outcome between surgically and non-surgically treated patients were found 4 years after surgery. In more recent studies [6,7], surgically treated patients showed improved satisfaction with treatment compared with conservatively treated; nevertheless no differences in clinical outcome between surgically and conservatively treated patients were observed.

Regards to the comparison between different surgical treatments, a review of the literature [8] demonstrates a greater reported incidence of long-term recurrent back and leg pain after aggressive disc removal but a greater reported incidence of recurrent disc herniation after limited disc removal.

The aim of this paper was to investigate the long-term results after surgical treatment for lumbar HD by performing a retrospective study on a series of 89 consecutive patients affected by lumbar HD, receiving different surgical treatments: a simple microdiscectomy (45 cases) or a microdiscectomy associated with the implantation of an interlaminar prosthesis (44 cases).

\section{Material and Methods}

A retrospective analysis of clinical and surgical records of patients affected by extruded lumbar H.D. and admitted to our Department between September 2008 and June 2010 has been performed. All patients have been submitted to surgery after failure of the conservative treatment long lasting minimum 2 months.

A total of 89 consecutive patients have been identified, by dividing them into two groups, according to the received surgical treatment:

Group A: 45 patients, submitted to simple microdiscectomy;

Group B: 44 patients, submitted to microdiscectomy and interlaminar device positioning.

*Corresponding author: Giancarlo Guizzardi, Professor of Neurosurgery,
Neurosurgical Department, University and City Hospital Careggi, Firenze, Italy, Tel: 390557947806; E-mail: euydgu@tin.it

Received January 13, 2014; Accepted February 24, 2014; Published February 28, 2014

Citation: Corriero OV, Morichi R, Vagaggini A, Paoli L, Guizzardi G (2014) Lumbar Herniated Disc Treated by Microdiscectomy Alone or Microdiscectomy Plus an Interlaminar Shock Absorbing Device: Retrospective Study with Minimum 3-Years Follow-Up. J Spine 3: 159. doi:10.4172/2165-7939.1000159

Copyright: (c) 2014 Corriero OV, et al. This is an open-access article distributed under the terms of the Creative Commons Attribution License, which permits unrestricted use, distribution, and reproduction in any medium, provided the original author and source are credited. 
Citation: Corriero OV, Morichi R, Vagaggini A, Paoli L, Guizzardi G (2014) Lumbar Herniated Disc Treated by Microdiscectomy Alone or Microdiscectomy Plus an Interlaminar Shock Absorbing Device: Retrospective Study with Minimum 3-Years Follow-Up. J Spine 3: 159. doi:10.4172/21657939.1000159

Page 2 of 4

All patients were operated on a single level.

No preliminary selection of patients was performed. The choice between simple standard microdiscectomy and microdiscectomy associated with an interlaminar device was random, depending on the surgeon's belief and habit. Patients' informed consensus was obtained as usual.

The 2 groups resulted homogeneously distributed as regards general and clinical data (Table 1).

Patients history, neurological examination specific to low back pain, back pain Visual Analogue Scale (VAS), Macnab Criteria with reference to quality of life (QoL) and incidence and severity of complications were collected and evaluated. Preoperative VAS and Macnab Criteria evaluation in both groups are reported in detail (Table 1).

Study visits consisted of preoperative visits and visits at follow-up time ( 3 to 5 years). The follow-up evaluation have been performed by an independent neurosurgeon (O.V.C.) who personally interviewed the patients and reviewed the instrumental controls.

The Visual Analogue Scale (VAS) is a well known and validated [9] measurement instrument from one (no pain) to ten (worst pain ever) that results easy and fast to be applied.

The Macnab Criteria were selected because they represent a very simple evaluation of Quality of Life (QoL) that allows for dividing patients after surgery into four different classes [10]:

1- Excellent, no-pain - No restriction of activity.

2- Good, only occasional pain that interfers with normal activity.

3- Fair, improved functional capacity but intermittent pain of severity that modify work or leisure activity.

4- Poor, no improvement.

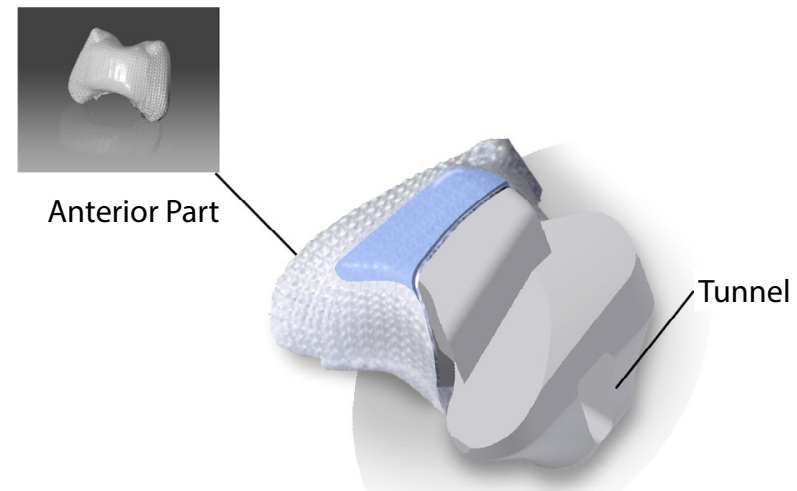

Figure 1: The interlaminar device (IntraSPINE $®)$.

\section{Surgical Techniques}

In all patients was performed a microdiscectomy according to Caspar [11].

The additional positioning of the interlaminar prosthesis, performed at the same time of the microdiscectomy, was accomplished according to Guizzardi et al. [12].

The key differences of the prosthesis we used, IntraSPINE ${ }^{\oplus}$ (Figure 1), when compared with other well-known interspinous devices, are the following:

- The rigid anterior part (Nose) positioned between the laminae, able to distract.

- The soft rear part (Tunnelled), compressible, does not limit the physiological movement of the spine.

- The inner part, silicone made, coated by a special tissue that promotes the penetration of fibroblasts.

- The adequate positioning, that is interlaminar, closer to the I.A.R. (Instantaneous Axis Rotation [13]).

The size of the device (available as 8-10-12-14-16 mm) was easily calculated by using the Trial included into the surgical dedicated set. The additional surgical time for the positioning of the prosthesis after microdiscectomy resulted between 15 and 25 minutes.

\section{Statistical analysis}

Clinical statistical analysis was performed by using paired T-test based on the comparison between preoperative and post-operative follow-up visits.

Success was assessed using a composite measure defined as:

1. decrease of back pain minimum of 4 points VAS;

2. minimum 1 level improvement in QoL;

3. absence of complications defined as reoperations, device removal or device related serious adverse events.

\section{Results}

The mean hospitalization time in 89 patients resulted between 36 and 72 hours. Surgical complications were absent in Group A. In 5 patients out of the Group B a sieroma (fluid collection) under the surgical wound that spontaneously disappeared was observed. No device removal was necessary; no device related severe adverse events were observed.

The follow-up ranges from minimum 3 to maximum 5 years. The independent observer was able to evaluate all 89 patients but one, out of the Group B, who resulted, lost to follow-up. Two recurrences resulted in Group A $(4,4 \%)$ and one in Group B (2,2\%).

\begin{tabular}{|c|c|c|c|c|c|c|}
\hline Study Group & No. & Sex & Mean Age & H.D.level & VAS* & Macnab \\
\hline $\begin{array}{c}\text { GROUP A } \\
\text { (Microdiscectomy) }\end{array}$ & 45 & $30 \mathrm{~m} ; 15 \mathrm{f}$ & $46.8 \mathrm{yrs}$ & $\begin{array}{l}\text { L2/L3: } 1 \\
\text { L3/L4: } 3 \\
\text { L4/L5: } 17 \\
\text { L5/S1: } 24\end{array}$ & $\begin{array}{c}\text { 1-3: } 0 \\
\text { 4-6: } 0 \\
7-10: 45\end{array}$ & $\begin{array}{c}\text { Macnab 1: } 0 \\
\text { Macnab 2: } 0 \\
\text { Macnab 3: } 10 \\
\text { Macnab 4: } 35\end{array}$ \\
\hline $\begin{array}{l}\text { GROUP B } \\
\text { ( Microdiscectomy+ } \\
\text { Interlaminar } \\
\text { Device) }\end{array}$ & 44 & $32 \mathrm{~m} ; 12 \mathrm{f}$ & 45.4 yrs & $\begin{array}{l}\text { L3/L4: } 1 \\
\text { L4/L5 : } 22 \\
\text { L5/S1: } 21\end{array}$ & $\begin{array}{c}\text { 1-3: } 0 \\
\text { 4-6: } 0 \\
7-10: 44\end{array}$ & $\begin{array}{c}\text { Macnab 1: } 0 \\
\text { Macnab 2: } 0 \\
\text { Macnab 3: } 8 \\
\text { Macnab 4: } 36\end{array}$ \\
\hline
\end{tabular}

*Visual Analogue Scale

Table 1 : General and Clinical data \& Preoperative Clinical Evaluation Specific to Low Back Pain in 89 patients. 
Citation: Corriero OV, Morichi R, Vagaggini A, Paoli L, Guizzardi G (2014) Lumbar Herniated Disc Treated by Microdiscectomy Alone or Microdiscectomy Plus an Interlaminar Shock Absorbing Device: Retrospective Study with Minimum 3-Years Follow-Up. J Spine 3: 159. doi:10.4172/21657939.1000159

Page 3 of 4

The follow-up evaluation showed an improvement in all 89 patients with statistical significance at the paired T-test $(\mathrm{p}<0.0001)$.

The instrumental results with the prosthesis were excellent (Figures $2 \mathrm{a}$ and $2 \mathrm{~b})$.

Among the 2 Groups no patient with Macnab 4 was observed at follow-up visit. The specific follow-up results in both groups of patients are shown in Table 2.

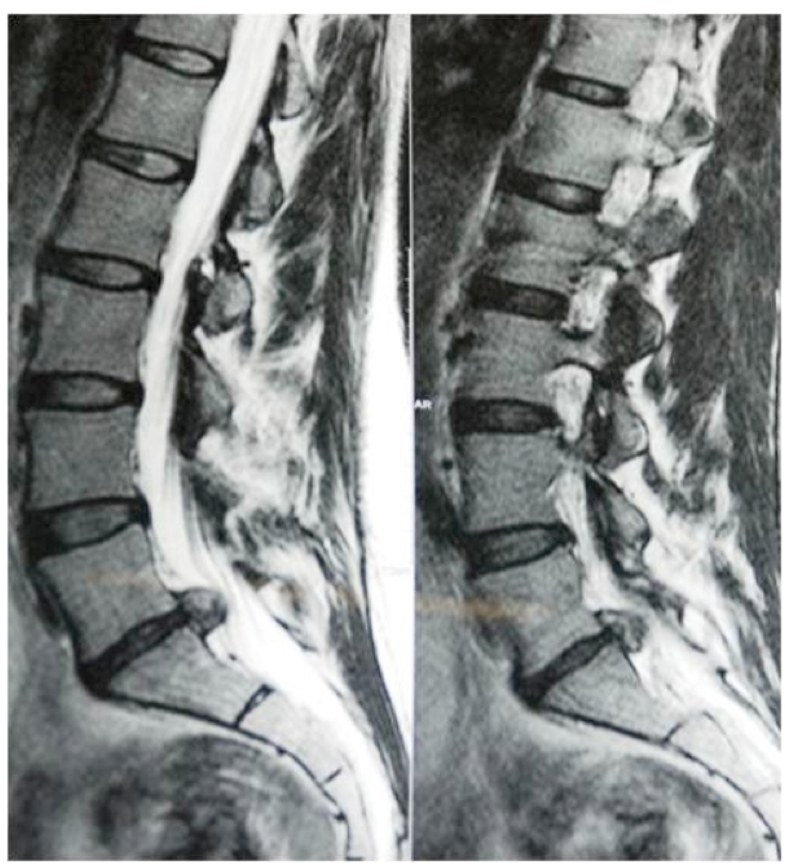

Figure 2 a: Preoperative Sagittal T2-weighted Magnetic Resonance, Group B patient \#18, showing an L5/S1 herniated disc.

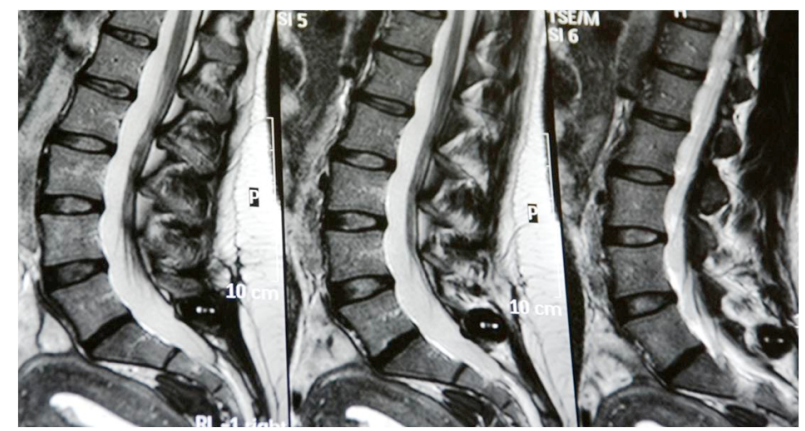

Figure 2 b: Sagittal T2-weighted Magnetic Resonance, after a 4-years follow-up.

\begin{tabular}{|c|c|c|}
\hline Study Group & $\begin{array}{c}\text { Visual Analogue Scale } \\
\text { (VAS) }\end{array}$ & Macnab Criteria \\
\hline GROUP A & $1-3: 18(41 \%)$ & Macnab 1: 18 $(40 \%)$ \\
(Microdiscectomy) & $4-6: 23(51 \%)$ & Macnab 2: 22 $(50 \%)$ \\
& $7-10: 4(8 \%)$ & Macnab 3: 5 (10\%) \\
Macnab 4: 0 \\
\hline GROUP B * & $1-3: 32(74 \%)$ & Macnab 1: 30(71\%) \\
(Microdiscectomy+ Interlaminar & $4-6: 9(21 \%)$ & Macnab 2: 10 $(22 \%)$ \\
Device) & $7-10: 2(5 \%)$ & Macnab 3: 3 $(7 \%)$ \\
& & Macnab 4: 0 \\
\hline
\end{tabular}

* Group B: 43 pts, 1 pt lost to follow-up

Table 2: Follow -up clinical results in 88 cases.
Up today no failures of the device or breakage of the spinous process have been observed.

\section{Discussion}

Low back pain is one of the most prevalent problems in industrialized countries [1-8] and often results in decline of QoL of the affected patients. Recurrent lumbar HD is the most common complication following primary open discectomy $[1-8,14,15]$. It is defined as recurrent back and/or leg pain after a definite pain-free period lasting at least 6 months from initial surgery $[14,15]$. It is important to differentiate recurrent disc herniation from postoperative epidural scar because the latter may not benefit from reoperation [16]. Treatment of recurrent lumbar HD includes aggressive medical management and surgical intervention $[7,8]$. Surgical techniques include conventional open herniated disc removal, minimally invasive open herniated disc removal, and open herniated disc removal with fusion [8,17-19]. Fusion is necessary in the presence of concomitant segmental instability or significant foraminal stenosis resulting from disc space collapse; unfortunately fusion is associated with complications and intensifies the stress to adjacent levels $[20,21]$.

Studies focused on risk factors of true recurrent HD at the same level and side, are few $[14,15]$.

The purpose of our Study was to evaluate the efficacy of an interlaminar device, in addition to a standard microdiscectomy, in low back pain recurrence preventing. The rationale for considering the positioning of an interlaminar device as a solution for avoiding the low back pain recurrence is the ability of the prosthesis to prevent the rapid disc space collapse after surgery by supporting the discal pump [22].

Furthermore the possibility of implanting this device (IntraSPINE ${ }^{\circledR}$ ) without the necessity of a larger surgical incision or of a second operation, represents an adjunctive advantage for patients that merits to be stressed.

The comparison between the 2 Study Groups shows the absence of low back pain during the follow-up period of 3 years minimum in $74 \%$ of patients who received the implant, while only $41 \%$ of patients treated by means of simple standard microdiscectomy remained pain free.

Furthermore uncomfortable low back pain was registered in $21 \%$ of patients of Group B against $51 \%$ out of Group A.

As regard Macnab Criteria evaluation, that expresses the QoL, 71\% of patients resulted Excellent and 22\% Good in the Group B, while $40 \%$ were Excellent and 20\% Good in the Group A.

Moreover poor results were not observed in both study Groups.

Our results suggest a positive impact on the ability as well as on return to work of patients but only after collecting a larger number of cases we will be able to perform a complete cost-effectiveness analysis to support the use of the device.

\section{Conclusion}

This retrospective study collects a limited number of patients and there is a need for a larger series, collected in a prospective manner with a well-defined study design, to confirm our observations and results and to draw definitive and complete conclusion.

Nevertheless we can affirm the goodness of the path undertaken, particularly in the presence of an appropriate follow-up for evaluation.

At this time we can only observe the ability of the prosthesis to favourably influence the outcome of the patients, as regard to the low 
Citation: Corriero OV, Morichi R, Vagaggini A, Paoli L, Guizzardi G (2014) Lumbar Herniated Disc Treated by Microdiscectomy Alone or Microdiscectomy Plus an Interlaminar Shock Absorbing Device: Retrospective Study with Minimum 3-Years Follow-Up. J Spine 3: 159. doi:10.4172/21657939.1000159

Page 4 of 4

back pain recurrence, and underline its capacity to prevent the rapid collapse of the disc space also supporting the discal pump.

\section{References}

1. Asch HL, Lewis PJ, Moreland DB, Egnatchik JG, Yu YJ, et al. (2002) Prospective multiple outcomes study of outpatient lumbar microdiscectomy: should 75 to $80 \%$ success rates be the norm? J Neurosurg 96: 34-44.

2. Shimia M, Babaei-Ghazani A, Sadat BE, Habibi B, Habibzadeh A (2013) Risk factors of recurrent lumbar disk herniation. Asian J Neurosurg 8: 93-96.

3. Silverplats K, Lind B, Zoëga B, Halldin K, Rutberg L, et al. (2010) Clinical factors of importance for outcome after lumbar disc herniation surgery: longterm follow-up. Eur Spine J 19: 1459-1467.

4. Weber H (1983) Lumbar disc herniation. A controlled, prospective study with ten years of observation. Spine (Phila Pa 1976) 8: 131-140.

5. Yorimitsu, Chiba K, Toyama Y, Hirabayashi K (2001) Long-term outcomes of standard discectomy for lumbar disc herniation: a follow-up study of more than 10 years. Spine (Phila Pa 1976) 26: 652-657.

6. Atlas SJ, Keller RB, Wu YA, Deyo RA, Singer DE (2005) Long term outcomes of surgical and non surgical management of sciatica secondary to a lumbar disc herniation: 10-year results from the Maine lumbar spine Study. Spine (Phila Pa 1976) 30: 927-935

7. Weinstein JN, Lurie JD, Tosteson TD, Skinner JS, Hanscom B, et al. (2006) Surgical versus nonoperative treatment for lumbar disc herniation: the Spine Patient Outcomes Research Trial (SPORT) observational cohort JAMA 296: 2451-2459.

8. McGirt MJ, Ambrossi GL, Datoo G, Sciubba DM, Witham TF, et al. (2009) Recurrent disc herniation and long-term back pain after primary lumbar discectomy: review of outcomes reported for limited versus aggressive disc removal. Neurosurgery 64: 338-345.

9. Knop C, Oeser M, Bastian L, Lange U, Zdichavsky M, et al. (2001) [Development and validation of the Visual Analogue Scale (VAS) Spine Score]. Unfallchirurg 104: 488-497.
10. Macnab I (1973) Chapter 14. Pain and disability in degenerative disc disease Clin Neurosurg 20: 193-196.

11. Caspar W (1977) A new surgical procedure for the lumbar herniation causing less tissue damage through a microsurgical approach. Adv Neurosurg 4: 74-77.

12. Guizzardi G, Petrini P, Morichi R, Mattioli CM, Scaglione V, et al. (2008) Italian Multicentric Study on the use of a new interlaminar prosthesis (IntraSPINE $®$ ) in DDD of lumbar spine: Preliminary report Eur Spine J. 17: 1603-1604.

13. Pearcy MJ, Bogduk N (1988) Instantaneous axes of rotation of the lumbar intervertebral joints. Spine (Phila Pa 1976) 13: 1033-1041.

14. Suk KS, Lee HM, Moon SH, Kim NH (2001) Recurrent lumbar disc herniation: results of operative management. Spine (Phila Pa 1976) 26: 672-676.

15. Lee JK, Amorosa L, Cho SK, Weidenbaum M, Kim Y (2010) Recurrent lumbar disk herniation. J Am Acad Orthop Surg 18: 327-337.

16. Rönnberg K, Lind B, Zoega B, Gadeholt-Göthlin G, Halldin K, et al. (2008) Peridural scar and its relation to clinical outcome: a randomised study on surgically treated lumbar disc herniation patients. Eur Spine J 17: 1714-1720.

17. Rogers LA (1988) Experience with limited versus extensive disc removal in patients undergoing microsurgical operations for ruptured lumbar discs. Neurosurgery 22 [Part 1]: 82-85.

18. Silvers HR (1988) Microsurgical versus standard lumbar discectomy. Neurosurgery 22: 837-841.

19. Kowalski JM, Olsewski JM, Simmons ED Jr (1995) Results of intervertebra diskectomy without fusion at L4-5 versus L5-S1. J Spinal Disord 8: 457-463.

20. Ritter LK, Dressler n, Schatz C, Gossel L, Beeman L (2013) Treatment of Lumbar degenerative Disc Disease Using a Novel, Compressible Core Prosthesis: 24-month results . J Spine 2: 147.

21. Soh J, Lee JC, Shin BJ (2013) Analysis of risk factors for adjacent segment degeneration occurring more than 5 years after fusion with pedicle screw fixation for degenerative lumbar spine. Asian Spine J 7: 273-281.

22. Martin MD, Boxell CM, Malone DG (2002) Pathophysiology of lumbar disc degeneration: a review of the literature. Neurosurg Focus 13: E1. 